\title{
New crosslinked hydrogels derivatives of 2-hydroxyethyl methacrylate: Synthesis, modifications and properties
}

\author{
B. Podkościelna*, A. Bartnicki, B. Gawdzik \\ Department of Polymer Chemistry, Faculty of Chemistry, Maria Curie-Sklodowska University, pl. M. Curie-Skłodowskiej 5, \\ 20-031 Lublin, Poland
}

Received 8 February 2012; accepted in revised form 16 April 2012

\begin{abstract}
This paper presents the synthesis, physicochemical properties and modifications of 2-hydroxyethyl methacrylate copolymers. It describes the new 2-hydroxyethyl methacrylate hydrogels in the form of microbeads of different degrees of crosslinking $(2,5,8,10,15$ and 20\% mol). As crosslinking monomers bis[4(2-hydroxy-3-methacryloyloxypropoxy) phenyl]-sulfide and ethylene glycol dimethacrylate were used. The new hydrogels were obtained by two alternative methods in a suspension copolymerisation procedure. The copolymers were modified with diethylenetriamine in an epoxide opening reaction. Thermal properties (differential scanning calorimetry, thermogravimetric analysis) and swelling characteristic in typical solvents of the obtained functional hydrogels were examined. The chemical structure of the copolymers before and after modification was confirmed by Fourier transform infrared spectroscopy and elemental analyses.

Moreover, their sorptive properties in removal of $\mathrm{Cu}(\mathrm{II}), \mathrm{Zn}(\mathrm{II}), \mathrm{Cd}(\mathrm{II})$, and $\mathrm{Pb}(\mathrm{II})$ ions from aqueous solutions were also presented. The Langmuir and Freundlich isotherm models are used to describe the adsorption characteristics of the selected modified hydrogels.
\end{abstract}

Keywords: polymer gels, microbeads, material testing, thermal properties, 2-hydroxyethyl methacrylate

\section{Introduction}

The first mention of hydrogels appeared in 1960 when Wichterle and Lim proposed the use of poly (2-hydroxyethyl methacrylate) in contact lenses [1]. Since then, the use of hydrogels has extended to various applications. Due to their excellent hydrophilic properties, high swelling ratio and biocompatibility, hydrogels have been widely used in agriculture, in biomedicine as antibacterial materials, biosensors and in tissue engineering, in sorbents for the removal of heavy metals, and many other applications $[2,3]$. These materials have been also used in the development of the smart drug delivery systems. Hydrogels can control drug release by changing the gel structure in response to environmental stimuli and also can protect the drug from hostile environments [4-6].

\footnotetext{
${ }^{*}$ Corresponding author, e-mail: beatapod@poczta.umcs.lublin.pl (c) BME-PT
}

Hydrogels based on 2-hydroxyethyl methacrylate (HEMA) copolymers are of a widespread interest in biomedical applications. Because of their high water content, hydrogels have a degree of flexibility similar to naturally occurring tissues, which minimises potential irritation to surrounding membranes and tissues [7].

For this reason, $\mathrm{pH}$ - and temperature-sensitive hydrogels, based on HEMA and itaconic acid copolymers, were prepared and characterised in order to examine their potential use in biomedical applications [8]. To improve their mechanical properties numerous modifications of $\mathrm{p}$ (HEMA) were introduced [9]. The results of these modifications were materials with new physico-chemical properties. Macroporous hydrogels based on HEMA are artificial biomaterials commonly used in tissue engineer- 
ing, including central nervous system repair [10]. Novel hydrogels consisting of different molar ratios of 2-hydroxyethyl methacrylate and acrylamide were prepared for specialty applications as sorbents for some common metal ions [11]. Additionally, 2hydroxyethyl methacrylate and its derivatives are also used in the treatment of eye diseases, and among others for the synthesis of artificial corneas [12-13]. Copolymerisation of sulfur-containing monomers with HEMA lead to the formation of new polymers with high biocompatibility and very good physical and chemical properties [14].

In order to obtain mechanically and thermally resistant hydrogels, their crosslinking is necessary. In our research we used as a crosslinking monomer bis[4 (2-hydroxy-3-methacryloyloxypropoxy)phenyl]sulfide (BES.DM) [15] or ethylene glycol dimethacrylate (EGDMA). BES.DM is a very interesting crosslinking monomer having in its construction methacrylic groups, aromatic rings and sulfide group. Our current studies are aimed at obtaining sorbents with reactive functional groups on the surface capable of extensive modifications.

Specific commercially available sorbents are very expensive and have rather selective applications. Our newly obtained sorbent - hydrogel is thermally and chemically resistant, can be stored in surrounding temperature and moreover is low-toxic.

This article includes synthesis new hydrogels based on 2-hydroxyethyl methacrylate as a heavy metal sorbent. The obtained hydrogels were in the form of microbeads of the following degrees of crosslinking: $2,5,8,10,15$ and $20 \%$ mol, BES.DM or EGDMA. Additionally, these hydrogels were obtained in two alternative procedures. The selected hydrogels were modified with diethylenetriamine in the epoxide opening reaction. Studies of thermal stability, swelling characteristics and sorption were carried out. The structures of the hydrogels before and after modification were confirmed by FTIR and elemental analysis.

Their sorptive properties in removal of $\mathrm{Cu}$ (II), $\mathrm{Zn}$ (II), $\mathrm{Cd}(\mathrm{II})$ and $\mathrm{Pb}$ (II) ions from aqueous solutions were also presented. The adsorption characteristics (by used the Langmuir and Freundlich isotherm models) and kinetics test results of selected modified hydrogels were studied.

\section{Experimental}

\subsection{Chemicals and eluents}

2-Hydroxyethyl methacrylate (HEMA) and ethylene glycol dimethacrylate (EGDMA) decan-1-ol were from Fluka AG (Buchs, Switzerland); $\alpha, \alpha^{\prime}-$ Azoiso-bis-butyronitrile (AIBN) and poly(vinyl pyrrolidone) (PVP; K90) were obtained from Merck (Darmstadt, Germany). Reagent grade acetone, methanol, propan-2-ol, chlorobenzene, chloroform, hexane, toluene, tetrahydrofurane (THF), methyl methylene, 1,4-dioxane, 2-(chloromethyl)oxirane (EP) and sodium hydroxide $(\mathrm{NaOH})$ were from POCh (Gliwice, Poland). Bis[4(2-hydroxy-3methacryloyloxypropoxy)phenyl]sulfide (BES.DM) was obtained by the procedure described in our previous work [15].

Aqueous solution of $\mathrm{CuCl}_{2} \cdot 2 \mathrm{H}_{2} \mathrm{O}, \mathrm{ZnCl}_{2}$, $\mathrm{Cd}\left(\mathrm{NO}_{3}\right)_{2} \cdot 4 \mathrm{H}_{2} \mathrm{O}$ and $\mathrm{Pb}\left(\mathrm{NO}_{3}\right)_{2}$ were used as sources of $\mathrm{Cu}(\mathrm{II}), \mathrm{Zn}$ (II), $\mathrm{Cd}$ (II) and $\mathrm{Pb}$ (II) respecively. The stock solution was further diluted to the required experimental concentration. Other chemicals used were of analytical grade.

\subsection{Synthesis of hydrogels}

\subsubsection{Synthesis of BES.DM-HEMA and} EGDMA-HEMA and their modifications

The experimental parameters of the syntheses of the copolymers are presented in Table 1.

The dispersion medium was prepared through the dissolution of $1 \mathrm{wt} \%$ poly(vinyl pyrrolidone) in deionised water $\left(150 \mathrm{~cm}^{3}\right)$. The synthesis was carried out in a three-necked flask equipped with a stirrer, a water condenser and a thermometer. The initiator AIBN $(1.5 \mathrm{wt} \%)$ was dissolved in the monomers, and then the mixture of BES.DM and HEMA or EGDMA and HEMA was diluted with a mixed solvent $\left(8 \mathrm{~cm}^{3}\right.$ toluene $/ 8 \mathrm{~cm}^{3}$ decan-1-ol). The reaction mixture was stirred at $350 \mathrm{rpm}$ for $12 \mathrm{~h}$ at $80^{\circ} \mathrm{C}$. The obtained copolymers were washed with distilled water, filtered off, dried and extracted (ace-

Table 1. Experimental parameters of the synthesis

\begin{tabular}{|c|c|c|c|c|c|}
\hline \multirow{2}{*}{ AIBN } & \multirow{2}{*}{ PVP } & \multirow{2}{*}{ HEMA } & \multirow{2}{*}{ EHEMA } & Crosslinker (20\% mol) \\
\cline { 4 - 6 } & & & BES.DM & EGDMA \\
\hline 0.249 & 1.50 & - & 10 & 6.66 & - \\
\hline 0.265 & 1.50 & 10 & - & 7.72 & - \\
\hline 0.206 & 1.50 & 10 & - & - & 3.76 \\
\hline
\end{tabular}


tone and methanol) in a Soxhlet apparatus. After drying in air, copolymers were fractionated with sieves. The applied polymerisation conditions yielded about $80 \%$ beads in the range of $40-80 \mu \mathrm{m}$.

\section{Modification with 2-(chloromethyl)oxirane}

The selected BES.DM-HEMA and EGDMA-HEMA copolymers were modified with 2-(chloromethyl) oxirane. In a $250 \mathrm{~cm}^{3}$ round bottomed three-necked flask equipped with a mechanical stirrer, a thermometer and a dropper of $10 \mathrm{~g}$ of selected beads was placed together with $80 \mathrm{~mL}$ 2-(chloromethyl)oxirane and $60 \mathrm{~mL}$ of propan-2-ol and the whole content was heated over a water bath at $70^{\circ} \mathrm{C}$. Then, at the same temperature $10 \mathrm{~mL}$ of $13.5 \%$ solution of $\mathrm{NaOH}$ were added during 5 minutes. After 15 minutes another portion $(50 \mathrm{~mL})$ of $13.5 \%$ solution of $\mathrm{NaOH}$ was added and the stirring was continued for 60 minutes. The obtained modified beads were filtered off, washed with aqueous methanol, next filtered off and dried.

\section{Modification with DETA}

In a $250 \mathrm{~cm}^{3}$ round-bottomed two-necked flask equipped with a mechanical stirrer and a thermometer, $10 \mathrm{~g}$ of selected microspheres (BES.DM-HEMAEP or EGDMA-HEMA-EP) was placed together with $10 \mathrm{~mL}$ diethylenetriamine (DETA) and $150 \mathrm{~mL}$ of toluene and the whole content was mixed at room temperature for $2 \mathrm{~h}$. Next, it was heated over a water bath at $80^{\circ} \mathrm{C}$ for $3 \mathrm{~h}$ and finally at room temperature for $24 \mathrm{~h}$. The obtained modified microbeads were washed with distilled water, filtered off, dried and extracted in a Soxhlet apparatus with boiling acetone for $5 \mathrm{~h}$. Finally, the product was dried under reduced pressure at $30^{\circ} \mathrm{C}$ [16].

\subsubsection{Synthesis of EHEMA and BES.DM-EHEMA}

In a $250 \mathrm{~cm}^{3}$ round-bottomed three-necked flask equipped with a mechanical stirrer, thermometer and dropper: 0.3 mole HEMA, 1.5 mole 2-(chloromethyl) oxirane, and $85 \mathrm{~mL}$ of propan-2-ol were placed and the whole content was heated over a water bath at $70^{\circ} \mathrm{C}$. Then, at the same temperature, $20 \mathrm{~mL}$ of $13.5 \%$ solution of $\mathrm{NaOH}$ were added during 10 minutes. After 30 minutes another portion of $13.5 \%$ solution of $\mathrm{NaOH}$ was added and the stirring was continued for 60 minutes. When the reaction was over, the content of the flask was placed into the dropper, the water layer was separated, and the organic layer was distilled at low pressure (1.6 kPa) in order to separate 2-propanol and the excess of 2-(chloromethyl) oxirane. The remaining 2-(chloromethyl)oxirane and water were distilled at low pressure after $50 \mathrm{~mL}$ of toluene was added into it. The obtained epoxide compound was filtered off. The main reaction product was a methacrylate (2,3-epichlorohydrin)ethyl.

\section{Copolymerisation}

The dispersion medium was prepared through the dissolution of $1 \mathrm{wt} \%$ poly(vinyl pyrrolidone) in deionised water $\left(150 \mathrm{~cm}^{3}\right)$. In a $250 \mathrm{~cm}^{3}$ round-bottomed three-necked flask equipped with a mechanical stirrer, thermometer and water condenser, EHEMA was placed together with BES.DM and AIBN (polymerization initiator), then the mixture was diluted with a mixed solvent $\left(8 \mathrm{~cm}^{3}\right.$ toluene/ $8 \mathrm{~cm}^{3}$ decan-1-ol) (Table 1). The reaction was stirred at $350 \mathrm{rpm}$ for $12 \mathrm{~h}$ at $80^{\circ} \mathrm{C}$. The obtained hydrogels were washed and filtered off according to the procedure presented previously. Next, the obtained microbeads with the pending epoxide groups were modified with diethylenetriamine according to the instructions given in Section 2.2.1.

\section{Characterisation}

Elemental analysis of the parent and modified copolymers was carried out using the Perkin-Elmer CHN 2400 apparatus.

Photos of the hydrogels were obtained using the scanning electron microscope Quanta 3D FEG SEM (FEI Company) with the use of ETD detector in high vacuum.

Fourier transform infrared spectroscopy (FTIR) spectra were recorded using a Perkin-Elmer $1725 \mathrm{X}$ spectrophotometer in the $400-4000 \mathrm{~cm}^{-1}$ wave number range using $\mathrm{KBr}$ pallets.

Differential scanning calorimetry (DSC) thermograms were obtained with the use of a DSC Netzsch 204 calorimeter (Netzsch, Günzbung, Germany) operating in a dynamic mode. The dynamic scans were performed at a heating rate of $10 \mathrm{~K} \cdot \mathrm{min}^{-1}$ at two temperature scans. The first scan was performed between $20^{\circ} \mathrm{C}$ and a maximum of $110^{\circ} \mathrm{C}$ to remove any adsorb moisture. The second one was conducted in $20-500^{\circ} \mathrm{C}$ under nitrogen atmosphere $\left(30 \mathrm{~mL} \cdot \mathrm{min}^{-1}\right)$. The mass of the sample was $\sim 10 \mathrm{mg}$. 
As a reference, an empty aluminum crucible was used. The glass transition temperature $\left(T_{\mathrm{g}}\right)$, decomposition temperature $\left(T_{\mathrm{d}}\right)$, and enthalpy of decomposition $\left(\Delta H_{\mathrm{d}}\right)$ were evaluated.

Thermogravimetric analysis (TG) was carried out on a Paulik and Erdey derivatograph (Budapest, Hungary) at a heating rate of $10^{\circ} \mathrm{C} \cdot \mathrm{min}^{-1}$ in air, in the temperature range of 20 to $1000^{\circ} \mathrm{C}$ with the sample weight of $100 \mathrm{mg}$. As a reference $\alpha-\mathrm{Al}_{2} \mathrm{O}_{3}$ was used. The initial decomposition temperature (IDT), $T_{20 \%}, T_{50 \%}$ of weight loss, final decomposition temperature $\left(T_{\text {end }}\right)$, and temperature of the maximum rate of weight loss $\left(T_{1}, T_{2}\right.$ and $\left.T_{3}\right)$ were determined.

The $\mathrm{HCl} /$ dioxane method [17] was used to determine the number of epoxy groups $\left(L_{\mathrm{EP}}\right)$. The epoxide content was calculated from the difference between the blank and that found for the titration of the sample reaction mixture.

The swellability coefficient, $B$, was determined by equilibrium swelling in methanol, acetone, toluene, 1,4-dioxane, THF, water, chlorobenzene and hexane. The samples were swollen in a few solvents for $0.5 \mathrm{~h}$. The excess solvents were removed by centrifugal methods $[18,19]$. Three specimens were tested for each hydrogels and a mean value was taken. $B$ is expressed as given by Equation (1):

$B=\frac{V_{\mathrm{s}}-V_{\mathrm{d}}}{V_{\mathrm{d}}} \cdot 100 \%$

where $V_{\mathrm{s}}$ is the volume of the copolymer after swelling and $V_{\mathrm{d}}$ - the volume of the dry copolymer.

\subsection{Adsorption tests}

The adsorption equilibrium measurements in the single component system were carried out at room temperature. $0.2 \mathrm{~g}$ of a polymer sample was placed in a $100 \mathrm{~mL}$ conical flask containing $20 \mathrm{~mL}$ of heavy metal ion solution with the initial concentration ranging from $1 \cdot 10^{-3}$ to $25 \cdot 10^{-3} \mathrm{M}$. The $\mathrm{pH}$ of the solution was maintained at 5.0 by using nitric $(\mathrm{V})$ acid to avoid metal precipitation using Elmetron CPI-505 pH/ionometer (Poland). The samples were shaken mechanically using the laboratory shaker (ELPHINE, type 357, Poland) for $24 \mathrm{~h}$ at $180 \mathrm{rpm}$. The preliminary experiments showed that equilibrium was reached under this condition. At equilibration, the concentrations of $\mathrm{Cu}(\mathrm{II}), \mathrm{Zn}(\mathrm{II}), \mathrm{Cd}(\mathrm{II})$ and $\mathrm{Pb}$ (II) in the residual solutions were analysed by the AAS (Atomic Absorption Spectrometry) measurements using SpectrAA 240FZ (Varian, Australia) at appropriate wavelengths, i.e. 324.7, $213.9,228.8$, and $217.0 \mathrm{~nm}$ for copper, zinc, cadmium and lead, respectively.

The adsorption data of the metal ions using the BES.DM-HEMA-EP-DETA sample was analysed according to the Langmuir and Freundlich models $[20,21]$.

The Langmuir equation has the following form given by Equation (2):

$q_{\mathrm{e}}=\frac{q_{0} K_{\mathrm{L}} c_{\mathrm{e}}}{1+K_{\mathrm{L}} c_{\mathrm{e}}}$

where $c_{\mathrm{e}}$ is the equilibrium concentration of the metal ion $[\mathrm{mg} / \mathrm{L}]$ and qe is the adsorption capacity at equilibrium $[\mathrm{mg} / \mathrm{g}]$.

Constant $q_{0}[\mathrm{mg} / \mathrm{g}]$ and $K_{\mathrm{L}}[\mathrm{L} / \mathrm{mg}]$ are the characteristics of the Langmuir equation and can be determined from its linearised form (plots of $c_{\mathrm{e}} / q_{\mathrm{e}} \mathrm{vs} . c \mathrm{e}$ ). The Freundlich equation is expressed by Equation (3):

$q_{\mathrm{e}}=K_{\mathrm{F}} c_{\mathrm{e}}^{1 / \mathrm{n}}$

where $K_{\mathrm{F}}$ is the Freundlich adsorption capacity $[\mathrm{mg} / \mathrm{g}]$ and $1 / n$ is the Freundlich constant related to the surface heterogeneity. The above equation can be linearised by taking logarithms to find the parameters $K_{\mathrm{F}}$ and $n$.

\subsection{Kinetic tests}

For evaluation the kinetic parameters the most commonly known kinetic expressions that is the pseudo first order kinetic and the pseudo second order kinetic models were used according to the Equations (4) and (5) [22]:

$$
\begin{aligned}
& \log \left(q_{1}-q_{\mathrm{t}}\right)=\log \left(q_{1}\right) \frac{k_{1}}{2.303} t \\
& \frac{1}{q_{\mathrm{t}}}=\frac{1}{k_{2} q_{2}^{2}}+\frac{1}{q_{2}} t
\end{aligned}
$$

where $q_{\mathrm{t}}$ is the amount of metal adsorbed at time $t$ $[\mathrm{mg} / \mathrm{g}], q_{1}, q_{2}$ are the amounts of metal complexes sorbed at equilibrium for the pseudo first order kinetic and the pseudo second order kinetic models $[\mathrm{mg} / \mathrm{g}]$, respectively, $k_{1}$ is the pseudo first order rate constant $[1 / \mathrm{min}]$ and $k_{2}$ is the rate constant of the pseudo second order adsorption $[\mathrm{g} /(\mathrm{mg} \cdot \mathrm{min})]$. 
Based on the plots of $\log \left(q_{\mathrm{e}}-q_{\mathrm{t}}\right)$ vs. $t$ and $t / q_{\mathrm{t}}$ vs. $t$ the kinetic parameters $\left(q_{1}, k_{1}, q_{2}, k_{2}, h\right)$ were calculated.

\section{Results and discussion}

Suspension polymerisation of prepared methacrylate monomers with HEMA in the presence of diluents (toluene + decan-1-ol) leads to polymeric hydrogels in form of microbeads. Experimental parameters of representative syntheses are summarised in Table 1.

Copolymerisation process was performed at a variable molar ratio of crosslinking monomers to $\operatorname{HEMA}(2,5,8,10,15$ and 20\% mol.) and constant volume ratio of diluents to monomers (1:1).

The scheme presenting theoretical chemical structures of the obtained new crosslinked hydrogels and products of their modification with DETA are presented in Figures 1 and 2. Elemental analysis of amine derivatives are presented in Table 2. From these data one can see that the highest percentage of nitrogen was achieved for BES.DM-EDETA (3.59\% $N_{\text {prac }}$ ). The percentage of nitrogen calculated from the number of epoxy group $\left(N_{\text {theo }}\right)$ is higher than that obtained during the synthesis $\left(N_{\text {prac }}\right)$. The difference probably results from a connection DETA mainly to the epoxy groups present on the surface of hydrogels.

Unfortunately, the epoxy derivative of EGDMAHEMA was characterised by a very low number of epoxy groups $(0.15 \mathrm{mmol} / \mathrm{g}$, Table 2$)$. As this reaction occurs with a low yield, studies of this derivative were not pursued. For further study copolymers BES.DM-HEMA and BES.DM-EHEMA were<smiles>C=C(C)C(=O)OCCOC(=O)C(=C)C</smiles><smiles>[3H]CC(=C)C(=O)OCC(O)COc1ccc(Sc2ccc(OCC(O)COC(=O)C(=C)C)cc2)cc1</smiles>

Copolymerization I

BES.DM-HEMA

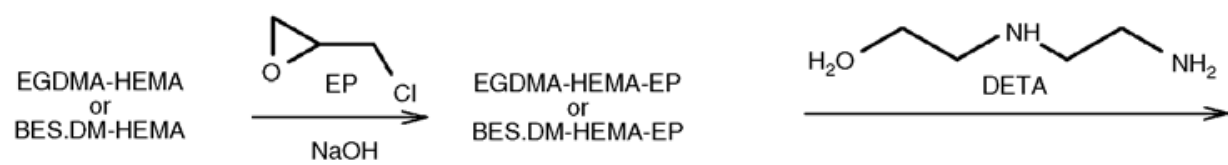<smiles>CCOC(=O)OCC(O)CNCCNCCN</smiles>

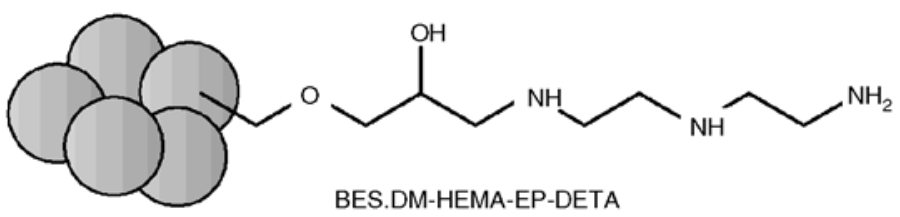

Modification I

Figure 1. Preparation scheme of HEMA hydrogels 
<smiles>C=C(C)C(=O)OCCOCCOC(=O)C(=C)C</smiles><smiles>C=C(C)C(=O)OCC(O)COc1ccc(Sc2ccc(OCC(O)COC(=O)C(=C)C)cc2)cc1</smiles>

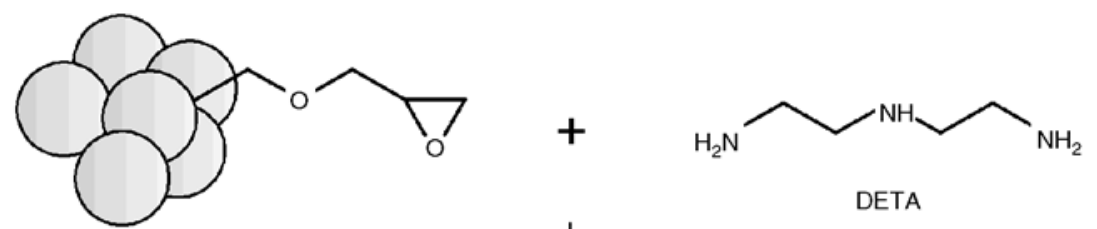

BES.DM-EHEMA<smiles>CCOCCNCCNCCNCCN</smiles>

Modification II

Figure 2. Preparation scheme of EHEMA hydrogel

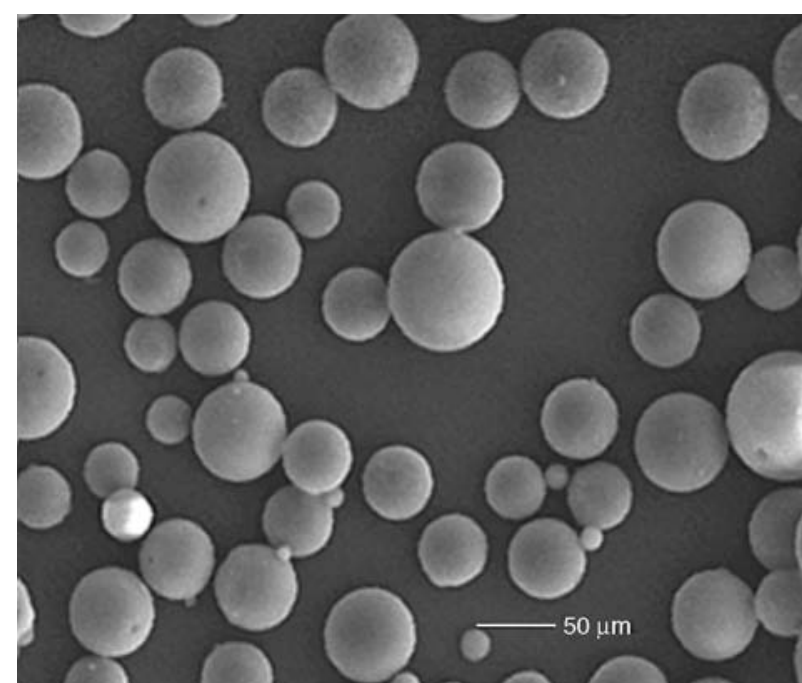

a)

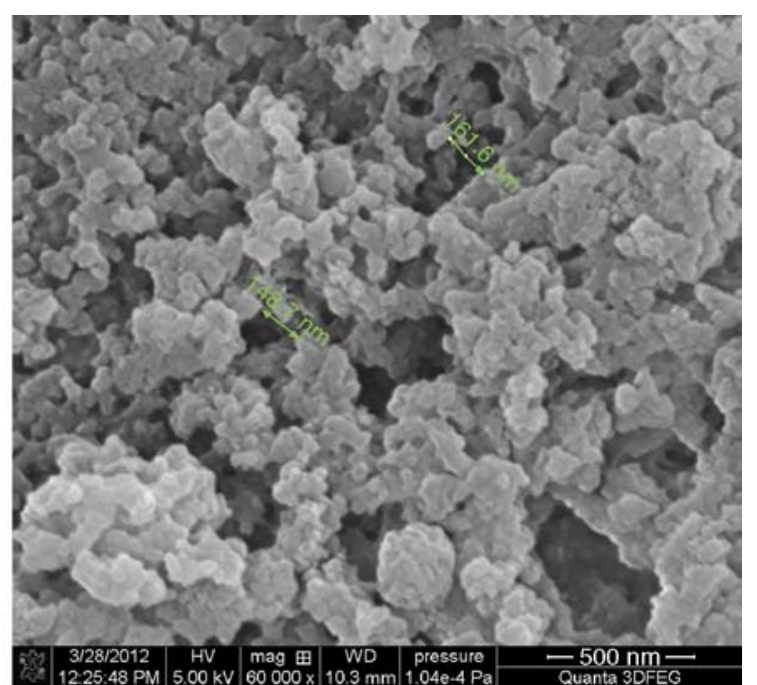

b)

Figure 3. SEM photos, a) BES.DM-EHEMA, b) fragment of surface

Table 2. Elemental analysis of amine derivatives

\begin{tabular}{|c|c|c|c|c|c|}
\hline Copolymer & $\mathrm{C}_{\text {prac }}$ & $\mathbf{H}_{\text {prac }}$ & $\mathbf{N}_{\text {prac }}$ & $\mathbf{N}_{\text {theo }}$ & $\mathbf{L}_{\mathrm{EP}}$ of epoxy derivatives \\
\hline & \multicolumn{4}{|c|}{$[\%]$} & {$[\mathrm{mmol} / \mathrm{g}]$} \\
\hline EGDMA-HEMA-EP-DETA & 58.52 & 7.31 & 0.81 & 1.86 & 0.15 \\
\hline BES.DM-HEMA-EP-DETA & 57.92 & 7.63 & 3.09 & 6.21 & 0.60 \\
\hline BES.DM-EHEMA-DETA & 57.52 & 7.17 & 3.59 & 7.50 & 0.74 \\
\hline
\end{tabular}

$N_{\text {prac }}$ - the percentage of nitrogen obtained in the synthesis

$N_{\text {theo }}$ - the theoretical percentage of nitrogen 
selected which were obtained with a molar ratio of $20 \%$ crosslinking monomer. The tests confirmed that the obtained microspheres were characterised by the greatest mechanical stability, which is necessary for further multi-step reactions (after several hours stirring the microbeads keep their spherical shape). The greater the degree of crosslinking, the greater the mechanical stability of hydrogels.

In order to confirm the spherical shape of the obtained hydrogels, two photos were taken by using the scanning electron microscope (SEM). In Figure $3 \mathrm{a}$, hydrogels are presented in a dry state, in Figure $3 \mathrm{~b}$ the fragment of the surface in higher magnification is visible.

\subsection{FTIR}

The chemical structures for new HEMA hydrogels and their derivatives were confirmed by FTIR analysis (Table 3 and Figure 4). The results shown in Figure 4 confirmed that modifications of BES.DMHEMA with 2-(chloromethyl)oxirane and respectively with DETA took place (the presence of epoxy group peak at $906 \mathrm{~cm}^{-1}$, and then its disappearance).

In the spectrum of the BES.DM-HEMA, C-H stretching vibrations of aromatic ring backbone methyl groups is observed at $2946 \mathrm{~cm}^{-1}$. The aromatic skeletal absorption is observed at $1591 \mathrm{~cm}^{-1}$. In the spectrum the vibrations of $-\mathrm{OH}$ group are visible at $3400 \mathrm{~cm}^{-1}$. The signal of $\mathrm{C}=\mathrm{O}$ group occurs at $1720 \mathrm{~cm}^{-1}$. In the spectrum BES.DMHEMA-EP, the epoxide group gives a shape signal at $906 \mathrm{~cm}^{-1}$. Moreover, in the spectrum BES.DMHEMA-EP-DETA, C-H stretching vibrations of aromatic ring backbone methyl groups is observed at $2943 \mathrm{~cm}^{-1}$, the aromatic skeletal at $159 \mathrm{~cm}^{-1}$ and $\mathrm{C}=\mathrm{O}$ group at $1721 \mathrm{~cm}^{-1}$.

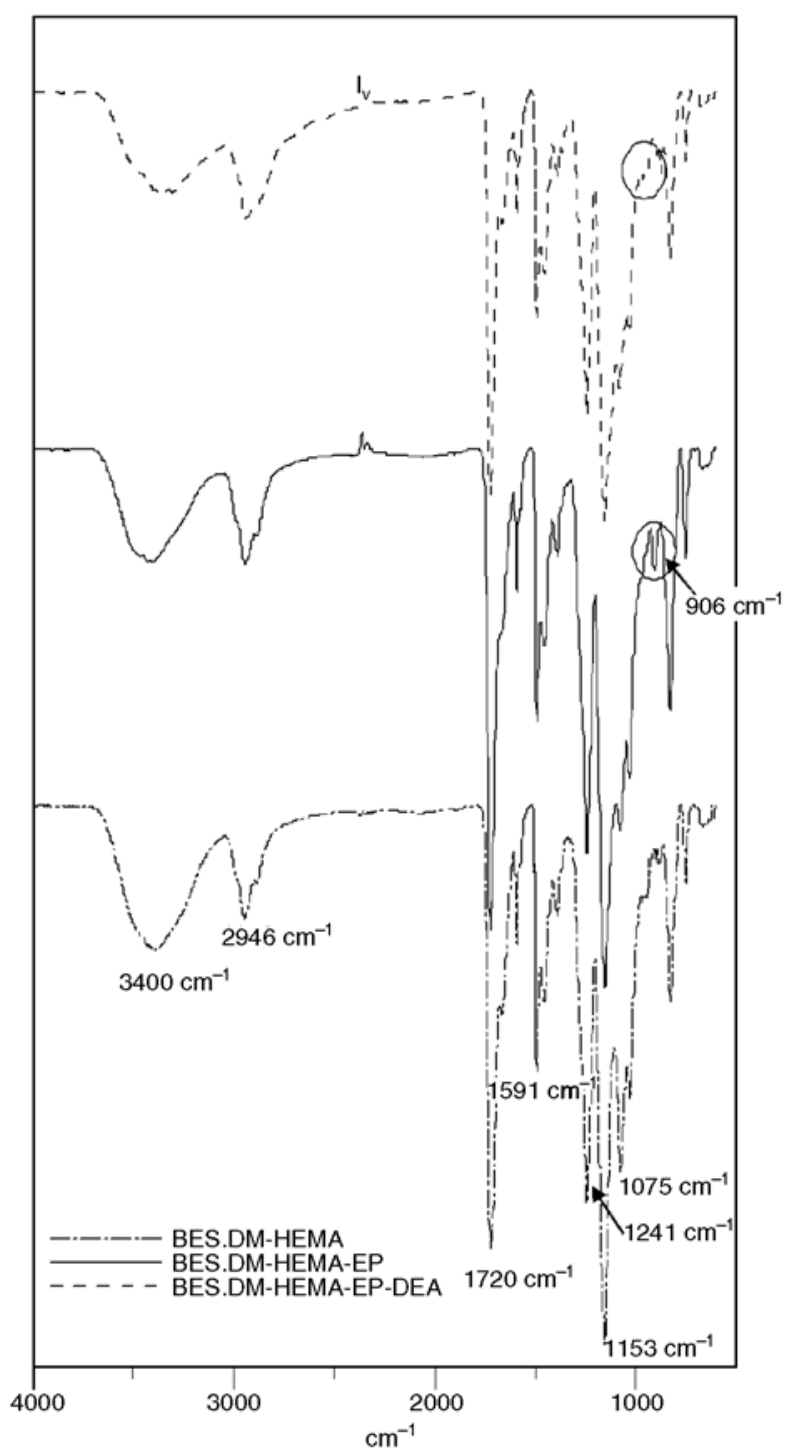

Figure 4. FTIR spectra of the BES.DM-HEMA derivatives

\subsection{Swelling properties}

The swelling properties of the studied microbeads are presented in Table 4. In all polar solvents the swellability coefficients $(B)$ varied from 33.1 to $214 \%$. Significantly higher values of $B$ in polar solvents compared to those values in non-polar hexane or

Table 3. FTIR analysis

\begin{tabular}{|c|c|c|c|c|c|}
\hline \multirow[b]{2}{*}{ Copolymer } & \multicolumn{5}{|c|}{$\left[\mathrm{cm}^{-1}\right]$} \\
\hline & & $\mathrm{OH}$ & & O & $-\mathrm{CH}_{3}$ \\
\hline EGDMA-HEMA & - & 3399 & - & 1719 & 2945 \\
\hline BES.DM-HEMA & 1591 & 3400 & - & 1720 & 2946 \\
\hline BES.DM-HEMA-EP & 1591 & 3400 & 906 & 1728 & 2945 \\
\hline BES.DM-HEMA-EP-DETA & 1591 & 3368 & - & 1721 & 2942 \\
\hline BES.DM-EHEMA & 1592 & 3435 & 906 & 1722 & 2946 \\
\hline BES.DM-EHEMA-DETA & 1592 & 3467 & - & 1721 & 2943 \\
\hline
\end{tabular}


Table 4. Swelling studies of obtained copolymers; swellability coefficient $-B$

\begin{tabular}{|c|c|c|c|c|c|c|c|c|}
\hline \multirow[b]{2}{*}{ BES.DM:HEMA } & Methanol & Acetone & Toluene & THF & Hexane & Chlorobenzene & Water & 1.4-Dioxane \\
\hline & \multicolumn{8}{|c|}{ B [\%] } \\
\hline $2 \%$ & 214.0 & 67.4 & 42.3 & 79.6 & 43.2 & 84.4 & 126.9 & 80.6 \\
\hline $5 \%$ & 192.4 & 60.7 & 37.8 & 64.9 & 38.8 & 76.4 & 106.6 & 70.1 \\
\hline $8 \%$ & 173.2 & 53.4 & 36.1 & 49.5 & 37.8 & 45.6 & 102.1 & 59.6 \\
\hline $10 \%$ & 122.4 & 38.6 & 29.8 & 46.1 & 33.5 & 32.2 & 90.0 & 54.9 \\
\hline $20 \%$ & 87.3 & 33.1 & 25.0 & 47.5 & 31.2 & 24.8 & 89.2 & 48.4 \\
\hline \multicolumn{9}{|l|}{ EGDMA:HEMA } \\
\hline $2 \%$ & 97.7 & 36.3 & 48.0 & 66.0 & 15.0 & 59.3 & 75.3 & 69.3 \\
\hline $5 \%$ & 90.4 & 35.3 & 36.4 & 64.6 & 15.4 & 44.7 & 63.7 & 63.9 \\
\hline $8 \%$ & 84.5 & 32.8 & 39.8 & 71.9 & 14.8 & 44.5 & 60.4 & 53.3 \\
\hline $10 \%$ & 82.6 & 28.3 & 31.4 & 50.7 & 14.6 & 36.7 & 50.9 & 59.0 \\
\hline $20 \%$ & 81.5 & 23.7 & 21.8 & 35.9 & 11.3 & 32.5 & 49.5 & 40.4 \\
\hline MOD-1 & 36.7 & 31.3 & 11.2 & 13.3 & 3.1 & 6.7 & 25.0 & 13.1 \\
\hline MOD-2 & 32.2 & 31.1 & 5.9 & 6.3 & 3.0 & 6.5 & 18.8 & 9.4 \\
\hline
\end{tabular}

MOD-1 = BES.DM-HEMA-EP-DETA $(20 \% \mathrm{~mol})$

MOD-2 = BES.DM-EHEMA-DETA (20\% mol)

toluene were observed. Such behaviour is probably due to the presence of polar pendant functional groups (hydroxyl groups) in the chemical structure of copolymers. The highest swellability coefficient is observed for the least crosslinked copolymer. With the increase of crosslinking the swelling of copolymers decreases, ranging in the polar methanol from 214 to $87.3 \%$, respectively. Moreover, BES.DMHEMA copolymers are characterised by a higher tendency to swell than EGDMA-HEMA copolymers. This is associated with the differences of the chemical structures of BES.DM and EGDMA monomers. BES.DM is a monomer containing aromatic rings, ester groups as well as a sulfur heteroatom in its structure. EGDMA possesses only ester groups in its chemical structure. Due to the spatial structure of the forming nets in the polymerisation process, copolymer BES.DM-HEMA allows better penetration of porogen diluents which are responsible for the formation of a more developed porous structure. Modified microspheres have much less tendency to swell. Probably due to that,

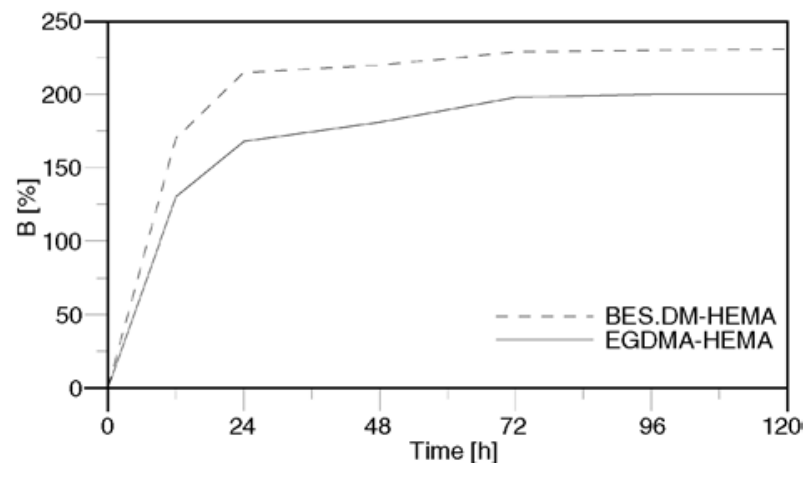

Figure 5. The swelling behaviour of hydrogels in water the hanging amino groups can block easy access of solvent into the hydrogel network.

The swelling behaviour of the studied microspheres in water is presented in Figure 5. From these data one can see that a maximum swelling is received after $24 \mathrm{~h}$ and that it does not increase any further. For the studied samples it changes from 160 to $220 \%$.

\subsection{Thermal properties}

The thermal properties of BES.DM-HEMA and EGDMA-HEMA copolymers as well as their amine derivatives were studied by means of DSC and TG analyses. The DSC was performed in a nitrogen atmosphere from 20 to $200^{\circ} \mathrm{C}$. The thermogravimetric analysis was conducted in air from 20 $1000^{\circ} \mathrm{C}$. The weight loss of $20 \%$ of copolymer $\left(T_{20 \%}\right)$ for the studied samples changes from 180 to $325^{\circ} \mathrm{C}$. The final decomposition temperatures $\left(T_{\text {end }}\right)$ are similar and are in the range $595-660^{\circ} \mathrm{C}$, Figure 6. The DTG curves contain three separate degradation steps. The first decomposition peak is observed in the range of $75-140^{\circ} \mathrm{C}$ with a maximum of weight loss $\left(T_{1}\right)$ at $90-130^{\circ} \mathrm{C}$. The second decomposition stage takes place between $180-400^{\circ} \mathrm{C}$ with $T_{2}$ at $200-575^{\circ} \mathrm{C}$, and the third is between 490 and $590^{\circ} \mathrm{C}$ with $T_{3}$ at $510-565^{\circ} \mathrm{C}$, Table 5 . The first decomposition peak could be associated with the loss of moisture, the second with the ester bonds breakdown in the structure of copolymers, while the third one could be attributed to the total degradation of copolymers. The obtained results are similar to our previous studies $[23,24]$. Copolymers modified by amines are characterised by insignificantly higher 

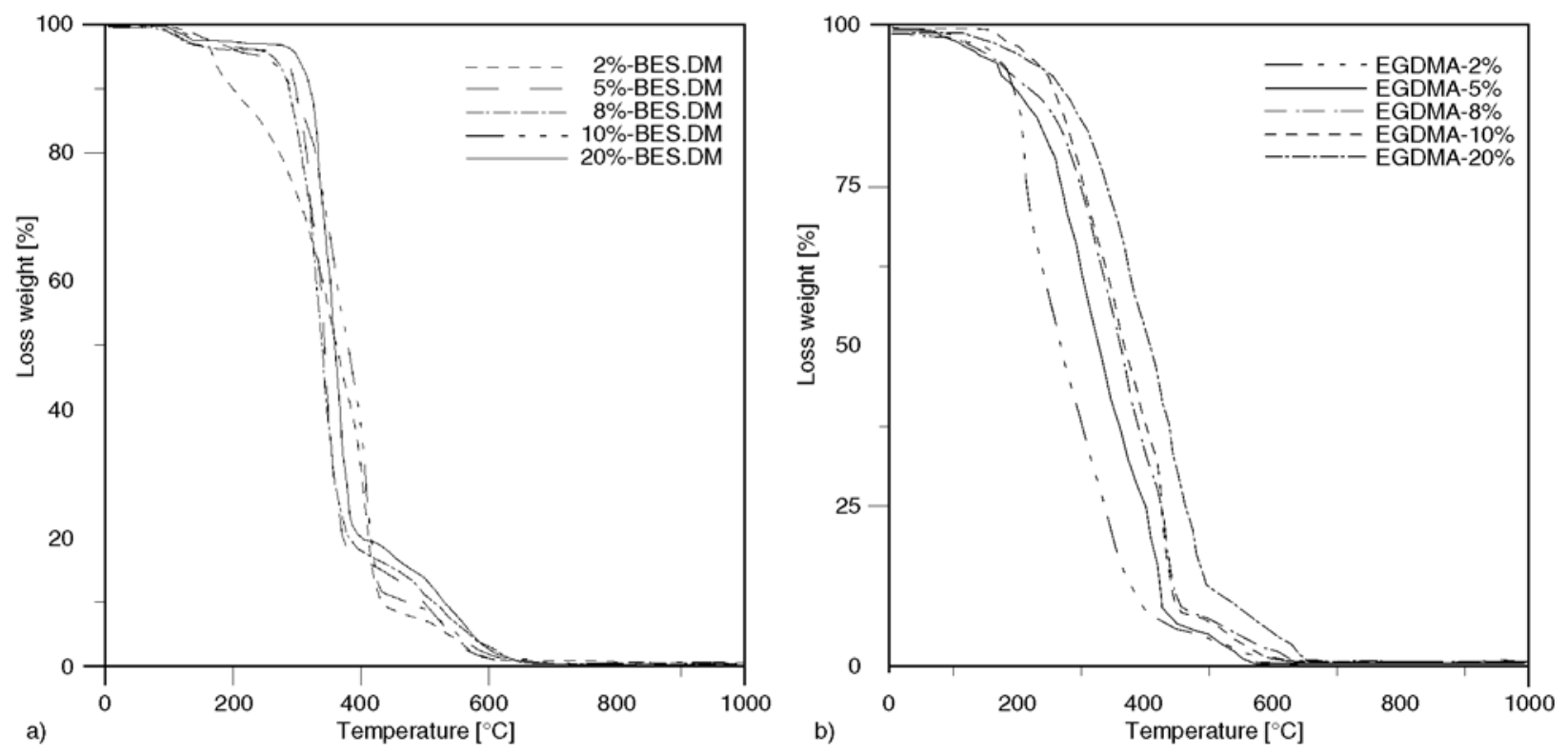

Figure 6. TG curves of the BES.DM-HEMA (a) and EGDMA-HEMA (b)

Table 5. Thermogravimetric analysis BES.DM-HEMA and EGDMA-HEMA

\begin{tabular}{|c|c|c|c|c|c|c|}
\hline $\begin{array}{c}\text { BES.DM:HEMA } \\
{[\% \text { mol }]}\end{array}$ & $\mathbf{T}_{\mathbf{2 0} \%}$ & $\mathbf{T}_{\mathbf{5 0} \%}$ & $\mathbf{T}_{\text {end }}$ & $\mathbf{T}_{\mathbf{1}}$ & $\mathbf{T}_{\mathbf{2}}$ & $\mathbf{T}_{\mathbf{3}}$ \\
\cline { 2 - 7 } & \multicolumn{7}{|c|}{$\left.{ }^{\circ} \mathbf{C}\right]$} \\
\hline $20: 80$ & 325 & 360 & 650 & 95 & 360 & 545 \\
\hline $10: 90$ & 325 & 390 & 645 & 105 & 380 & 565 \\
\hline $8: 92$ & 310 & 360 & 660 & 90 & 335 & 560 \\
\hline $5: 95$ & 320 & 365 & 640 & 95 & 350 & 560 \\
\hline $2: 98$ & 265 & 370 & 650 & 92 & 320 & 550 \\
\hline EGDMA:HEMA [\% mol] $]$ \\
\hline 20:80 & 260 & 340 & 600 & 130 & 320 & 540 \\
\hline 10:90 & 240 & 350 & 595 & 120 & 290 & 530 \\
\hline $8: 92$ & 240 & 340 & 600 & 120 & 310 & 535 \\
\hline $5: 95$ & 220 & 280 & 620 & 90 & 230 & 520 \\
\hline $2: 98$ & 180 & 250 & 605 & 95 & 200 & 510 \\
\hline MOD-1 & 285 & 360 & 715 & 80 & 340 & 565 \\
\hline MOD-2 & 280 & 370 & 720 & 80 & 350 & 560 \\
\hline
\end{tabular}

MOD- 1 = BES.DM-HEMA-EP-DETA $(20 \% \mathrm{~mol})$

MOD-2 = BES.DM-EHEMA-DETA $(20 \% \mathrm{~mol})$

temperatures of decomposition. In these cases additional bonds must be broken.

The DSC analysis confirmed these observations. The DSC curves of parent and modified copolymers are presented in Figure 7. Generally, DSC analysis shows similarity in thermal behaviour of all prepared copolymers. However, some differences for modified copolymers can be observed. As shown in Figure 7, copolymers BES.DM-HEMA (2 and $20 \% \mathrm{~mol}$ ) are characterised by one endothermic peak at about $120^{\circ} \mathrm{C}$, whereas for EGDMA with HEMA copolymers its maximum is at about $85^{\circ} \mathrm{C}$. These endothermic peaks at $83.3-125.4^{\circ} \mathrm{C}$ are connected with the loss of water present in the struc- ture of the polymer network. The analysis of the DTA and DSC of modified microbeads show the presence of adsorbed water on the amine groups.

\subsection{Adsorption test results}

Among sorption materials, the most popular are those containing nitrogen donor atoms which have high adsorption capacity and adsorption selectivity towards transition metal ions. 2-Hydroxyethyl methacrylate hydrogels modified by the compounds containing amino groups such as diethylenetriamine (DETA) can be widely used for the adsorption and separation of metal ions via coordination bond formation or ion exchange at appropriate $\mathrm{pH}$. It is known that the adsorption of the chelating resin towards metal ions must be considered as a liquidsolid phase reaction which includes the diffusion of the ions from the solution to the resin surface, the diffusion of the ions within the solid resin beads, and the coordination reaction between the ions and the amine groups of the resin. The above mentioned factors affect the adsorption process.

In the presented paper the sorption parameters of BES.DM-HEMA-EP-DETA hydrogel were evaluated based on the Langmuir and Freundlich isotherm models. They are the most commonly used to describe the adsorption characteristics of the sorbents. The Langmuir constants $q_{0}$ and $K_{\mathrm{L}}$ are related to the adsorption capacity and the energy of adsorption, respectively. The Freundlich model is applied to non-ideal sorption on heterogeneous surfaces as 

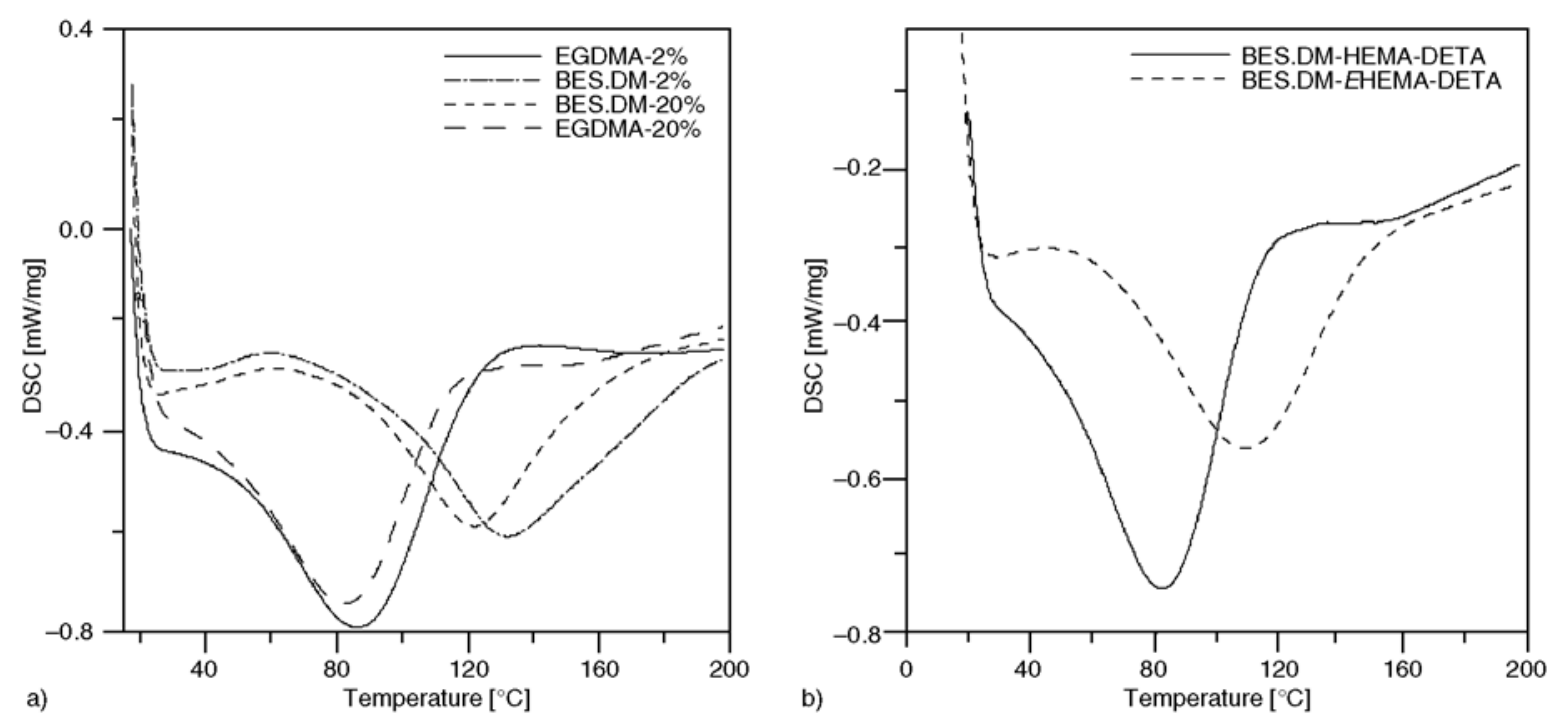

Figure 7. DSC curves, a) parent and b) modified hydrogels
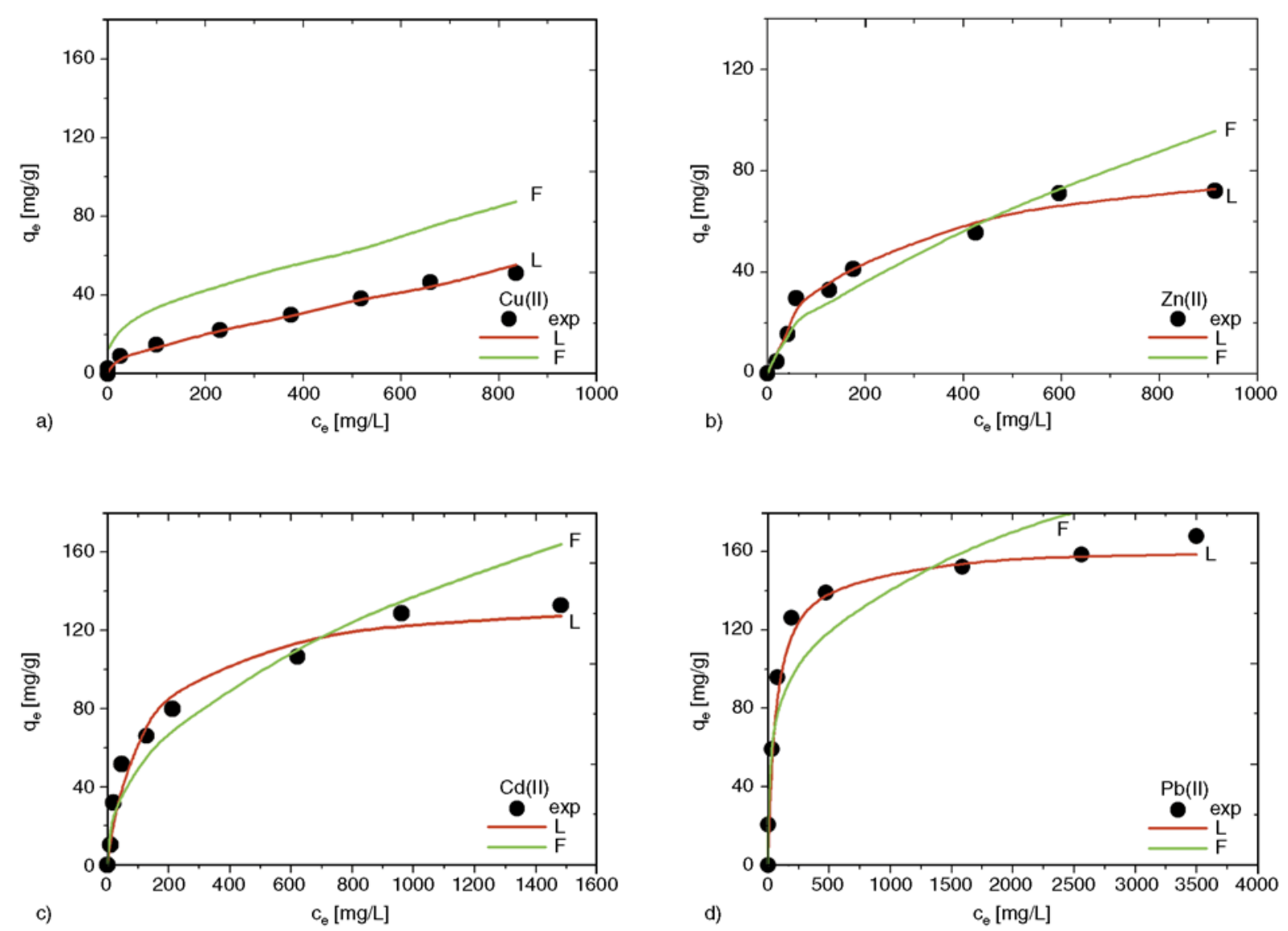

Figure 8. Correlation between the experimental adsorption curve and the calculated data by the Langmuir and Freundlich isotherm models in BES.DM-HEMA-EP-DETA (a) $\mathrm{Cu}$ (II), (b) $\mathrm{Zn}(\mathrm{II})$, (c) Cd(II) and (d) Pb(II)

well as multilayer adsorption. In this case the higher values of the $K_{\mathrm{F}}$ indicate a higher affinity for the metal ions in the sorbents used. The values of $n$ between 1 and 10 indicate favourable adsorption [25]. The Langmuir equation corresponds to a dominant ion exchange mechanism, while the Freund- lich isotherm shows the adsorption-complexation reactions taking place in the adsorption process [26]. The obtained sorption parameters based on the above-mentioned models are presented in Table 6 . Figure $8 \mathrm{a}-\mathrm{d}$ shows the correlation between the experimental adsorption curve and the calculated 
Table 6. The Langmuir and Freundlich isotherm constants for $\mathrm{Cu}(\mathrm{II}), \mathrm{Zn}(\mathrm{II}), \mathrm{Cd}(\mathrm{II})$ and $\mathrm{Pb}(\mathrm{II})$ adsorption on BES.DM-HEMA-EP-DETA

\begin{tabular}{|c|c|c|c|c|c|}
\hline \multicolumn{2}{|c|}{ System } & Cu(II) & Zn(II) & Cd(II) & Pb(II) \\
\hline \multicolumn{2}{|c|}{$\mathbf{q}_{\text {e,exp }}$} & $\mathbf{4 5 . 1 3}$ & $\mathbf{7 3 . 0 8}$ & $\mathbf{1 3 2 . 8 2}$ & $\mathbf{1 6 8 . 0 1}$ \\
\hline \multirow{3}{*}{ Langmuir } & $q_{0}$ & 47.01 & 72.88 & 136.99 & 161.29 \\
\cline { 2 - 6 } & $K_{\mathrm{L}}$ & 0.012 & 0.05 & 0.009 & 0.016 \\
\cline { 2 - 6 } & $R^{2}$ & 0.9587 & 0.9641 & 0.9826 & 0.9997 \\
\hline \multirow{3}{*}{ Freundlich } & $K_{\mathrm{F}}$ & 0.89 & 1.32 & 6.70 & 27.98 \\
\cline { 2 - 6 } & $n$ & 1.22 & 1.59 & 2.28 & 4.19 \\
\cline { 2 - 6 } & $R^{2}$ & 0.9231 & 0.8813 & 0.8772 & 0.9467 \\
\hline
\end{tabular}

data by the Langmuir and Freundlich isotherm models on BES.DM-HEMA-EP-DETA. The better fitting of the experimental data by the Langmuir model was established based on the $R^{2}$ values (Table 6). It was found that for the Langmuir model these values were in the range 0.9587-0.9997, whereas for the Freundlich one they were 0.8772 0.9467 .

Based on the Langmuir isotherm model the maximum adsorption capacities $\left(q_{0}\right)$ of BES.DM-HEMAEP-DETA are $0.74 \mathrm{mmol} / \mathrm{g}$ for $\mathrm{Cu}(\mathrm{II}), 1.11 \mathrm{mmol} / \mathrm{g}$ for $\mathrm{Zn}(\mathrm{II}), 1.23 \mathrm{mmol} / \mathrm{g}$ for $\mathrm{Cd}(\mathrm{II})$ and $0.78 \mathrm{mmol} / \mathrm{g}$ for $\mathrm{Pb}(\mathrm{II})$ (Table 6). It should be also mentioned that the calculated values of sorption capacities (qo,cal) are comparable with those obtained experimentally $\left(q_{\mathrm{e}, \text { exp }}\right)$ and can generally be put in the order: $\mathrm{Cd}(\mathrm{II})>\mathrm{Zn}(\mathrm{II})>\mathrm{Pb}(\mathrm{II})>\mathrm{Cu}(\mathrm{II})$. Over the last decades numerous studies regarding metal sorption on hydrogels with different functionalities were published. Among different modifying factors ammonia, etylenediamine, dietyltriamine have should be mentioned. However, there are few data regarding chelating properties of such obtained materials. In papers by Atia et al. [27] as well as Senkal and Bicak [28] the poly(GMA-co-EGDMA) polymers modified among over by diethylenetriamine were used. They found that the sorption capacity for $\mathrm{Ca}(\mathrm{II})$ and $\mathrm{Mg}(\mathrm{II})$ depends on the type of the ligand and was the highest for DETA. In the case of DETA the concentration of amino groups is higher by 1.15 times compared to those with ethylenediamine (EDA). In the paper by Maksin et al. [29] the porous and nonporous crosslinked poly(glycidyl methacrylate-coethylene glycol dimethacrylate) were prepared by suspension copolymerization and functionalized with diethylenetriamine. They found that the maximum adsorption capacity at $\mathrm{pH} 1.8$ was $143 \mathrm{mg} / \mathrm{g}$ for PGME2-DETA. The amine derivatives have also been developed by incorporating the monoamino-, diamino- and triamino- ligands into various families of mesoporous ordered silicas [30].

\subsection{Kinetics test results}

The effects of the phase contact time on the sorption capacities of BES.DM-EHEMA-DETA towards $\mathrm{Cu}(\mathrm{II}), \mathrm{Zn}(\mathrm{II}), \mathrm{Cd}(\mathrm{II})$ and $\mathrm{Pb}(\mathrm{II})$ ions $\left(1.0 \cdot 10^{-3} \mathrm{M}\right.$, shaking speed $180 \mathrm{rpm}$, temperature $298 \mathrm{~K}$ ) are presented in Figure 9. Taking into account that the characteristics of adsorption behaviour are generally inferred in terms of both adsorption kinetics and equilibrium isotherms in the next stage the kinetic test were carried out. Predicting the adsorption rate as well as the adsorbate residence time and the reactor dimensions controlled by the kinetic, are probably the most important factors in the adsorption system design. The preliminary results for the BES.DM-HEMA-EP-DETA hydrogel samples were presented to evaluate the sorption kinetics. The calculated kinetic parameters for $\mathrm{Cu}(\mathrm{II}), \mathrm{Zn}(\mathrm{II}), \mathrm{Cd}(\mathrm{II})$ and $\mathrm{Pb}(\mathrm{II})$ in BES.DM-EHEMA-DETA are pre-

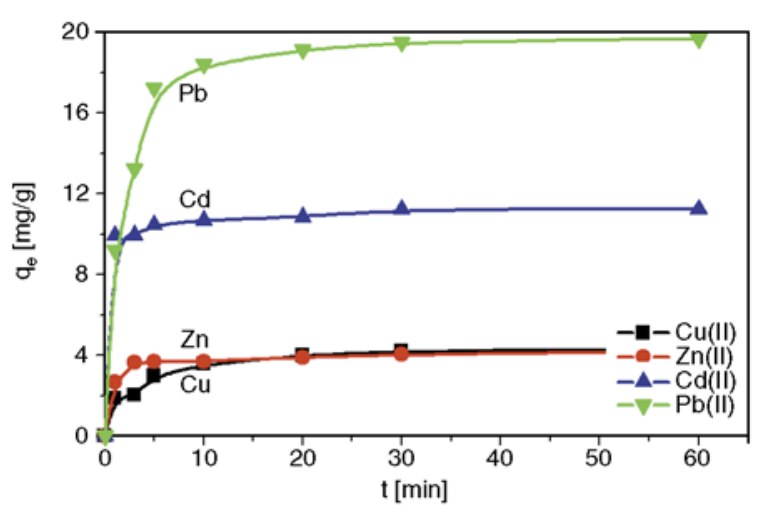

Figure 9. Effect of the phase contact time on the sorption capacities of BES.DM-EHEMA-DETA towards $\mathrm{Cu}(\mathrm{II}), \mathrm{Zn}(\mathrm{II}), \mathrm{Cd}(\mathrm{II})$ and $\mathrm{Pb}(\mathrm{II})$ ions

Table 7. The kinetic parameters for $\mathrm{Cu}(\mathrm{II}), \mathrm{Zn}(\mathrm{II}), \mathrm{Cd}(\mathrm{II})$ and $\mathrm{Pb}(\mathrm{II})$ on BES.DM-EHEMA-DETA

\begin{tabular}{|l|c|c|c|c|c|c|c|c|}
\hline \multirow{2}{*}{$\mathbf{M}(I I)$} & \multicolumn{4}{|c|}{ PF-order model } & \multicolumn{4}{c|}{ PS-order model } \\
\cline { 2 - 10 } & $\mathbf{q}_{\mathbf{e}, \mathbf{e x p}}$ & $\mathbf{q}_{\mathbf{1}}$ & $\mathbf{k}_{\mathbf{1}}$ & $\mathbf{R}^{\mathbf{2}}$ & $\mathbf{q}_{\mathbf{2}}$ & $\mathbf{k}_{\mathbf{2}}$ & $\mathbf{h}$ & $\mathbf{R}^{\mathbf{2}}$ \\
\hline $\mathrm{Cu}(\mathrm{II})$ & 4.31 & 1.234 & 0.023 & 0.9553 & 2.34 & 0.127 & 2.231 & 0.9992 \\
\hline $\mathrm{Zn}(\mathrm{II})$ & 4.20 & 1.426 & 0.045 & 0.9619 & 4.25 & 0.200 & 3.625 & 0.9993 \\
\hline $\mathrm{Cd}(\mathrm{II})$ & 10.54 & 2.488 & 0.187 & 0.9582 & 10.582 & 0.417 & 46.729 & 0.9998 \\
\hline $\mathrm{Pb}(\mathrm{II})$ & 19.69 & 7.667 & 0.171 & 0.9852 & 20.450 & 0.023 & 9.506 & 0.9999 \\
\hline
\end{tabular}


sented in Table 7. From these data one can see that the experimental values of sorption capacities $\left(q_{\mathrm{e}, \mathrm{exp}}\right)$ are comparable with those obtained by the pseudo second-order model $\left(q_{2}\right)$.

\section{Conclusions}

This work includes new, alternative methods of synthesising polymeric microbeads with active groups on the surface that may be useful in ion exchanging process.

New hydrogels were synthesised obtained by suspension polymerisation of 2-hydroxyethyl methacrylate with bis[4(2-hydroxy-3-methacryloyloxypropoxy) phenyl]sulfide or ethylene glycol dimethacrylate. Their hydroxyl functional groups were exploited for introduction of amine groups on the surface using epoxy compounds as intermediates. In preparation of epoxy compounds two procedures were applied.

The swelling and thermal properties of the new hydrogels were studied. Their swelling in water achieved maximum $220 \%$. Similar swelling is observed in methanol whereas in other organic solvents its values were significantly lower. Thermal studies suggest that modification led to an increase of their thermal resistances.

Application of the obtained new hydrogels in sorption of metal ions from water indicate that they are effective sorbents, especially for lead ions.

\section{References}

[1] Wichterle O., Lim D.: Hydrophilic gels for biological use. Nature, 185, 117-118 (1960). DOI: $10.1038 / 185117 \mathrm{a} 0$

[2] Inoue T., Chen G., Nakamae K., Hoffman A. S.: A hydrophobically-modified bioadhesive polyelectrolyte hydrogel for drug delivery. Journal of Controlled Release, 49, 167-176 (1997).

DOI: 10.1016/S0168-3659(97)00072-2

[3] Wang J., Wu W.: Swelling behaviors, tensile properties and thermodynamic studies of water sorption of 2hydroxyethyl methacrylate/epoxy methacrylate copolymeric hydrogels. European Polymer Journal, 41, 11431151 (2005).

DOI: 10.1016/j.eurpolymj.2004.11.034

[4] Qiu Y., Park K.: Environment-sensitive hydrogels for drug delivery. Advanced Drug Delivery Reviews, 53, 321-339 (2001). DOI: $10.1016 / \mathrm{S} 0169-409 X(01) 00203-4$
[5] Lin G., Chang S., Kuo C-H., Magda J., Solzbacher F.: Free swelling and confined smart hydrogels for applications in chemomechanical sensors for physiological monitoring. Sensors and Actuators B: Chemical, 136, 186-195 (2009).

DOI: $10.1016 /$ j.snb.2008.11.001

[6] Liu F., Urban M. W.: Recent advances and challenges in designing stimuli-responsive polymers. Progress in Polymer Science, 35, 3-23 (2010).

DOI: $10.1016 /$ j.progpolymsci.2009.10.002

[7] Gupta P., Vermani K., Garg S.: Hydrogels: From controlled release to $\mathrm{pH}$-responsive drug delivery. Drug Discovery Today, 7, 569-579 (2002).

DOI: 10.1016/S1359-6446(02)02255-9

[8] Tomić S. L., Mićić M. M., Dobić S. N., Filipović J. M., Suljovrujić E. H.: Smart poly(2-hydroxyethyl methacrylate/itaconic acid) hydrogels for biomedical application. Radiation Physics and Chemistry, 79, 643649 (2010).

DOI: 10.1016/j.radphyschem.2009.11.015

[9] Chang C., Duan B., Cai J., Zhang L.: Superabsorbent hydrogels based on cellulose for smart swelling and controllable delivery. European Polymer Journal, 46, 92100 (2010).

DOI: 10.1016/j.eurpolymj.2009.04.033

[10] Hejčl A., Lesný P., Přádný M., Śedý J., Zámečnik J., Jendelová P., Michálek J., Syková E.: Macroporous hydrogels based on 2-hydroxyethyl methacrylate. Part 6: 3D hydrogels with positive and negative surface charges and polyelectrolyte complexes in spinal cord injury repair. Journal of Materials Science: Materials in Medicine, 20, 1571-1577 (2009).

DOI: $10.1007 / \mathrm{s} 10856-009-3714-4$

[11] Chauhan G. S., Chauhan S., Sen U., Garg D.: Synthesis and characterization of acrylamide and 2-hydroxyethyl methacrylate hydrogels for use in metal ion uptake studies. Desalination, 243, 95-108 (2009). DOI: $10.1016 /$ j.desal.2008.04.017

[12] Chirila T. V.: An overview of the development of artificial corneas with porous skirts and the use of PHEMA for such an application. Biomaterials, 22, 3311-3317 (2001).

DOI: $10.1016 / \mathrm{S} 0142-9612(01) 00168-5$

[13] Chirila T. V., Hicks C. R., Dalton P. D., Vljayasekaran S., Lou X., Hong Y., Clayton A. B., Ziegelaar B. W., Fitton J. H., Platten S., Crawford G. J., Constable I. J.: Artificial cornea. Progress in Polymer Science, 23, 447-473 (1998).

[14] Kultys A.: Sulfur-containing polymers. in 'Encyclopedia of polymer science and technology’ (eds.: Mark H. F.) Wiley, New York (2010). DOI: $\underline{10.1002 / 0471440264 . p s t 355 . p u b 2}$ 
[15] Podkościelna B., Bartnicki A., Gawdzik B.: Porous microspheres, copolymers of bis[4-(2-hydroxy- 3methacryloyloxypropoxy)phenyl]sulfide, and divinylbenzene as stationary phase for HPLC. Journal of Applied Polymer Science, 111, 1257-1267 (2009). DOI: 10.1002/app.29154

[16] Podkościelna B.: Synthesis, modification, and porous properties of new glycidyl methacrylate copolymers. Journal of Applied Polymer Science, 120, 3020-3026 (2011).

DOI: 10.1002/app.33420

[17] PN-C-89085:1974: Uncured epoxy resins. Methods of testing (in Polish) (1974).

[18] Tuncel A., Pişkin A.: Nonswellable and swellable poly(EGDMA) microspheres. Journal of Applied Polymer Science, 62, 789-798 (1996).

DOI: 10.1002/(SICI)1097-4628(19961031)62:5<789::

$$
\text { AID-APP11>3.0.CO;2-O }
$$

[19] Kesenci K., Tuncel A., Pişkin E.: Swellable ethylene glycol dimethacrylate-hydroxyethylmethacrylate copolymer beads. Reactive and Functional Polymers, 31, 137-147 (1996).

DOI: $10.1016 / 1381-5148(96) 00052-1$

[20] Langmuir I.: The constitution and fundamental properties of solids and liquids. Part I. Solids. Journal of the American Chemical Society, 38, 2221-2295 (1916). DOI: $10.1021 / \mathrm{ja} 02268 \mathrm{a} 002$

[21] Freundlich H. F. M.: Über die Adsorption in Lösungen. Zeitschrift für Physikalische Chemie, 57, 385470 (1906).

[22] Ketcha Mbadcam J., Anagho S. G., Ndi Nsami J., Kammegne A. M.: Kinetic and equilibrium studies of the adsorption of lead (II) ions from aqueous solution onto two Cameroon clays: Kaolinite and smectite. Journal of Environmental Chemistry and Ecotoxicology, 3, 290-297 (2011).

[23] Podkościelna B., Worzakowska M.: Synthesis, characterization, and thermal properties of diacrylic/divinylbenzene copolymers. Journal of Thermal Analysis and Calorimetry 101, 235-241 (2010). DOI: $10.1007 / \mathrm{s} 10973-009-0574-6$
[24] Podkościelna B.: The highly crosslinked dimethacrylic/ divinylbenzene copolymers. Characterization and thermal studies. Journal of Thermal Analysis and Calorimetry, 104, 725-730 (2011).

DOI: $10.1007 / \mathrm{s} 10973-010-1184-\mathrm{Z}$

[25] Podkościelna B.: The use of bis[4(2-hydroxy-3methacryloyloxypropoxy)phenyl]sulfide in preparation of microspheres with pendant amine groups as a heavy metal sorbent. Separation Science and Technology, in press (2012).

[26] Yang C-H.: Statistical mechanical study on the Freundlich isotherm equation. Journal of Colloid and Interface Science, 208, 379-387 (1998).

DOI: $10.1006 /$ jcis. 1998.5843

[27] Atia A. A., Donia A. M., Abou-El-Enein S. A., Yousif A. M.: Studies on uptake behaviour of copper(II) and lead(II) by amine chelating resins with different textural properties. Separation and Purification Technology, 33, 295-301 (2003).

DOI: $10.1016 /$ S1383-5866(03)00089-3

[28] Şenkal B. F., Biçak N.: Glycidyl methacrylate based polymer resins with diethylene triamine tetra acetic acid functions for efficient removal of $\mathrm{Ca}$ (II) and $\mathrm{Mg}(\mathrm{II})$. Reactive and Functional Polymers, 49, 151157 (2001).

DOI: $10.1016 / \mathrm{S} 1381-5148(01) 00075-\mathrm{X}$

[29] Maksin D. D., Nastasović A. B., Milutinović-Nikolić A. D., Suručić L. T., Sandić Z. P., Hercigonja R. V., Onjia A. E.: Equilibrium and kinetics study on hexavalent chromium adsorption onto diethylene triamine grafted glycidyl methacrylate based copolymers. Journal of Hazardous Materials, 209-210, 99-110 (2012). DOI: $10.1016 /$ j.jhazmat.2011.12.079

[30] Aguado J., Arsuaga J. M., Arencibia A., Lindo M., Gascón V.: Aqueous heavy metals removal by adsorption on amine-functionalized mesoporous silica. Journal of Hazardous Materials, 163, 213-221 (2011). DOI: $10.1016 / j . j h a z m a t .2008 .06 .080$ 